\title{
Prediction and Analysis of Engine Friction Power of a Diesel Engine Influenced by Engine Speed, Load, and Lubricant Viscosity
}

\author{
Devendra Singh, ${ }^{1,2}$ Fengshou Gu, ${ }^{1}$ John D. Fieldhouse, ${ }^{1}$ Nishan Singh, ${ }^{2}$ and S. K. Singal ${ }^{2}$ \\ ${ }^{1}$ University of Huddersfield, Queensgate, Huddersfield, West Yorkshire HD1 3DH, UK \\ ${ }^{2}$ Indian Institute of Petroleum, Mohkampur, Haridwar Road, Dehradun, Uttarakhand 248005, India \\ Correspondence should be addressed to Devendra Singh; devendra@iip.res.in
}

Received 7 August 2014; Revised 15 October 2014; Accepted 16 October 2014; Published 9 December 2014

Academic Editor: Michel Fillon

Copyright (C) 2014 Devendra Singh et al. This is an open access article distributed under the Creative Commons Attribution License, which permits unrestricted use, distribution, and reproduction in any medium, provided the original work is properly cited.

Automotive industries made a paradigm shift in selection of viscometrics of engine lubricant, from higher to lower viscosity grade, for improving fuel economy of vehicles. Engine fuel consumption is influenced by friction between the various engine components. Engine friction power (FP) of a direct injection diesel engine is calculated from the measured value of in-cylinder pressure signals at various operating conditions. For predicting FP, as a function of speed, load, and lubricant viscosity, a full factorial design of experiments (DOE) was formulated and an empirical correlation was developed. Response surface methodology (RSM) was used for analyzing the dominant parameters and their interactions, which influence engine friction power significantly. Predicted results of engine FP are in good agreement with measured values at all operating points. ANOVA and RSM analysis revealed that the significant parameters influencing engine FP are speed, load, viscosity, speed-load, and speed-viscosity. The effect of engine lubricant viscosity on friction power of a diesel engine was insignificant at low speed, whereas, at high speed, it played a vital role. The empirical relation developed for predicting FP is very useful in estimating engine friction power for various combinations of engine speeds, loads, and lubricant viscosity without running the engine.

\section{Introduction}

Engine friction study has been a topic of research for many years. Some of the conventional methods like Morse test, PV diagram, Willans Line method, and motoring test for measuring friction of an engine are described in the literature [1]. It is widely accepted that PV diagram method yields more accurate results about engine friction. Total engine mechanical friction losses for a diesel engine were studied by Taylor [2] and Comfort [3]. It was highlighted that the majority of mechanical friction losses inside the engine emanated by piston ring assembly and bearings, which amounts to approximately $65 \%$ to $70 \%$ of the total mechanical friction losses. To achieve the better fuel efficiency, one must concentrate on reduction of these friction losses.

Researchers have extensively studied the friction of critical engine components, such as piston ring assembly, bearings, valve train system, and engine powered auxiliaries (such as the water pump, oil pump, fuel pump, etc.), theoretically as well as experimentally. Gligorijevic et al. [4] studied the effect of lubricant's viscosity on the fully warmed up diesel engine friction power loss $(W)$-which includes piston ring assembly $(P)$, valve train $(V)$, and bearing $(B)$. It was reported that the total friction power losses for the lower viscosity grade oil (SAE 10W-30) were $8 \%$ lower than the high viscosity grade oil (SAE 20W-50). The friction power loss of piston ring assembly reduces from $52 \%$, for SAE $20 \mathrm{~W}-50$, to $36 \%$ for SAE $10 \mathrm{~W}$ 30 lubricants. Similar trend was also observed in case of bearing. Taylor et al. [5] and Furuhama and Sasaki [6] reported the friction power losses in the piston assembly vary with viscosity as $\sqrt{ } \eta \omega$, where $\eta$ was the lubricant dynamic viscosity $(\mathrm{mPa} \cdot \mathrm{s})$ and $\omega$ is the angular speed $(\mathrm{rad} / \mathrm{s})$ of the engine. Taylor [7] studied the sensitivity of a 2.0 litre gasoline engine and its component's friction; it was stated that lower viscosity grade lubricant helps in reducing friction of bearings and piston assembly. For a heavily loaded bearing, it was reported 
that the friction power loss would vary with viscosity as $\eta^{0.75}$. Effects of engine oil viscosity on fuel consumption were studied by Taylor and others; it has been reported that low viscosity oil results in low fuel consumption $[8,9]$.

Some of the recent works of Mufti et al. [10-12] on investigating the influence of engine operating conditions and engine lubricant rheology on the distribution of power loss at engine component levels are remarkable. He also predicted piston ring assembly friction loss under realistic fired conditions of a single cylinder gasoline engine using the indicated mean effective pressure (IMEP) method and validated the model through experimental study. Friction modeling of tribofilm performance was studied by Roshan et al. [13] using statistical approach and response surface methodology (RMS). The developed model is based on a bench tribometer and is only pertinent to boundary and mixed lubrication. Dagostino et al. [14] have done an in-depth theoretical analysis of the friction interaction between the upper compression ring and the cylinder wall taking into account the mixed lubrication (ML) regime and considering different engine operating conditions, lubricant viscosity, and surface roughness. Through simulation, it was inferred that under high speed and low load conditions, the friction is in the hydrodynamic lubrication regime and the viscosity of the lubricant plays a major role in this region. The oil with low viscosity exhibits lower friction force for high speed and low radial load, while the high viscosity has better effect on the mechanical efficiency on the opposite side.

From the literature review, it emerged that piston ring assembly and bearings are predominantly operating in the hydrodynamic lubrication regime under high speed and low load conditions and engine oil viscosity plays a vital role in reducing friction, emanated during hydrodynamic lubrication regime. Principal factors which influence engine friction power are speed, load, oil film thickness, oil viscosity, oil temperature, surface topography of engine components, and type of friction modifiers used. The main objective of this paper is to develop a model to predict the engine friction power of a fired diesel engine based on significant factors (speed, load, and engine oil viscosity) and its interaction, using response surface methodology (RSM).

\section{Materials and Methods}

Experiments were conducted on a four stroke, four-cylinder, direct injection, heavy duty diesel engine coupled with the AC dynamometer and instrumented with fuel flow meter, pressure sensor, angle encoder, speed sensor, temperature indicators, data acquisition system, and so forth. For acquiring in-cylinder combustion pressure signals a piezoelectric pressure transducer, Kistler type 6125A, was used to calculate indicated mean effective pressure (IMEP), indicated power, and brake power (BP) for determining friction power. The pressure sensor was mounted in the combustion chamber of cylinder number one. The pressure sensor, polystable quartz elements, does not require additional cooling as it has been specially designed to work in high temperatures and for precision measurement of pressure of internal combustion engines. Engine oil temperature and coolant outlet
TABLE 1: Engine specifications.

\begin{tabular}{llc}
\hline 1 & Engine type & $\begin{array}{c}\text { Off-highway, DI diesel } \\
\text { engine turbocharged }\end{array}$ \\
2 & Displacement & $4399 \mathrm{cc}$ \\
3 & Compression ratio & $18.3: 1$ \\
4 & Number of cylinders & 4 \\
5 & Number of valves & 16 \\
6 & Fuel injection & Direct injection \\
7 & Maximum power output & $74.2 \mathrm{~kW} @ 2200 \mathrm{rpm}$ \\
\hline
\end{tabular}

TABLE 2: Physical characteristics of both engine lubricants.

\begin{tabular}{lcc}
\hline Properties & Oil SAE 10W-30 & Oil SAE 15W-40 \\
\hline Viscosity @ 40 $\mathrm{C}$ cst & 72 & 110 \\
Viscosity @ 100 $\mathrm{C}$ cst & 11.0 & 14.5 \\
Viscosity Index & 143 & 137 \\
\hline
\end{tabular}

temperatures were controlled within $90 \pm 5^{\circ} \mathrm{C}$ and $85-90^{\circ} \mathrm{C}$, respectively, throughout the experiments. A brief specification of the test engine, used for the study, is given in Table 1 and schematic of engine test bench is shown in Figure 1.

2.1. Engine Lubricants. Engine lubricants used in this experimental study are as follows:

\section{Reference oil SAE $15 \mathrm{~W}-40$ \\ Candidate oil SAE $10 \mathrm{~W}-30$}

Both engine lubricants are commercially available and complied to API CG-4 performance category level. Typical physical characteristics of both engine lubricants are shown in Table 2. Engine lubricants were chosen in such a way that both lubricants were comprising the same additive package but are of different viscosity grade.

2.2. Methodology and Design of Experiments. Indicated mean effective pressure (IMEP) in bar was computed after measuring in-cylinder combustion pressure signals for each operating point by using a matlab programme. Indicated power (IP) in $\mathrm{kW}$ was calculated from measured IMEP and brake power (BP) in $\mathrm{kW}$ was measured from engine dynamometer. Friction powers (FP) in $\mathrm{kW}$ for operating points were then calculated by subtracting brake power (BP) from indicated power (IP), under steady state conditions for both engine lubricants. Variation of oil viscosity with temperature may be neglected since all experiments were conducted in a controlled temperature of oil and coolant.

For predicting engine friction power of a diesel engine, as a function of speed, load, and engine oil viscosity, a full factorial design of experiments (DOE) was formulated. Statistical design of experiment (DOE) is an efficient tool for optimizing the variables in such a way that response variables yield the desired results. Description of factors and its levels are given in Table 3 and number of replicates was chosen as two; hence a total of 24 experiments were performed. Based on analysis of variance (ANOVA) results, significant factors were 


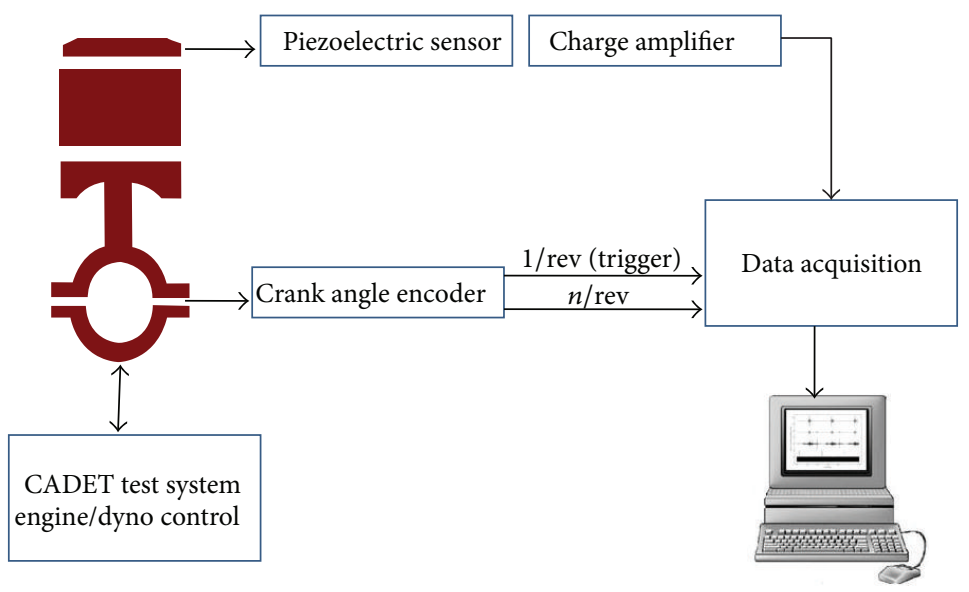

FIGURE 1: Schematic Engine test bench setup.

TABLE 3: Factors with its levels of experiment.

\begin{tabular}{lc}
\hline Factors & Levels \\
\hline Speed, rpm $(A)$ & 1000,2000 \\
Load, Nm $(B)$ & $50,200,350$ \\
Oil viscosity, cSt @ $100^{\circ} \mathrm{C}(C)$ & $11.0,14.5$ \\
\hline
\end{tabular}

identified and an empirical correlation was developed using a general regression equation for predicting the friction power of a diesel engine as a function of speed, load, and oil viscosity. Response surface methodology (RSM) was used for identifying the dominant parameters and their interactions influencing engine friction power significantly within 95\% confidence level.

\section{Result and Discussions}

Before discussing the test results, it is important to understand the relationship of friction power with speed, load, film thickness, oil viscosity, and cylinder pressure. Present research work is focused on the investigation of friction power as a function of engine speed, load, and oil viscosity, and engine components operating predominantly in hydrodynamic regime (piston ring assembly and bearings) are considered as major contributors towards engine friction power loss.

It is assumed that piston rings-liner pair is operating in hydrodynamic lubrication regime at high engine speed. Hence the governing equation for piston ring/liner could be Reynolds equation. A schematic of hydrodynamic oil film between liner and piston ring assembly is shown in Figure 2. Stachowiak and Batchelor [15] described the full Reynolds equation in three dimensional Euclidian spaces for any bearing as

$$
\begin{aligned}
& \frac{\partial}{\partial x}\left(\frac{h^{3} \partial P}{\partial x}\right)+\frac{\partial}{\partial y}\left(\frac{h^{3} \partial P}{\partial y}\right) \\
& \quad=6 \eta\left(\frac{U d h}{d x}+\frac{V d h}{d y}\right)+12 \eta \frac{d h}{d t}
\end{aligned}
$$

TABLE 4: Full factorial design of experiments comprising variables speed, load, oil viscosity, and response variable friction power (FP)

\begin{tabular}{|c|c|c|c|c|}
\hline Run order & Speed (rpm) & Load $(\mathrm{Nm})$ & Viscosity (cSt) & $\mathrm{FP}(\mathrm{kW})$ \\
\hline 1 & 2000 & 200 & 14.5 & 10.95 \\
\hline 2 & 2000 & 50 & 11 & 10.04 \\
\hline 3 & 1000 & 350 & 11 & 2.58 \\
\hline 4 & 2000 & 350 & 14.5 & 2.67 \\
\hline 5 & 1000 & 200 & 14.5 & 2.28 \\
\hline 6 & 1000 & 50 & 14.5 & 1.77 \\
\hline 7 & 2000 & 200 & 11 & 7.02 \\
\hline 8 & 1000 & 50 & 11 & 2.1 \\
\hline 9 & 2000 & 350 & 11 & 1.33 \\
\hline 10 & 1000 & 50 & 11 & 2.52 \\
\hline 11 & 1000 & 350 & 14.5 & 2.22 \\
\hline 12 & 2000 & 50 & 14.5 & 12.17 \\
\hline 13 & 2000 & 50 & 14.5 & 12.78 \\
\hline 14 & 2000 & 350 & 14.5 & 4.84 \\
\hline 15 & 1000 & 200 & 11 & 1.91 \\
\hline 16 & 1000 & 200 & 11 & 2.03 \\
\hline 17 & 1000 & 200 & 14.5 & 2.53 \\
\hline 18 & 2000 & 200 & 14.5 & 10.12 \\
\hline 19 & 1000 & 50 & 14.5 & 1.92 \\
\hline 20 & 2000 & 350 & 11 & 2.83 \\
\hline 21 & 1000 & 350 & 14.5 & 2.85 \\
\hline 22 & 2000 & 50 & 11 & 9.95 \\
\hline 23 & 1000 & 350 & 11 & 2.58 \\
\hline 24 & 2000 & 200 & 11 & 9.78 \\
\hline
\end{tabular}
in $\mathrm{kW}$.

Simplifying this equation for piston ring, by assuming an infinitely long bearing, very small width as compared to the circumferential length, pressure gradient in circumferential direction can be neglected; that is, $\partial P / \partial y=0$. And also velocity in $y$ direction is assumed to be zero; that is, $V=0$ and $U$ is piston velocity, " $h$ " is film thickness, and " $\eta$ " is dynamic viscosity of lubricant; assuming there is no vertical flow 


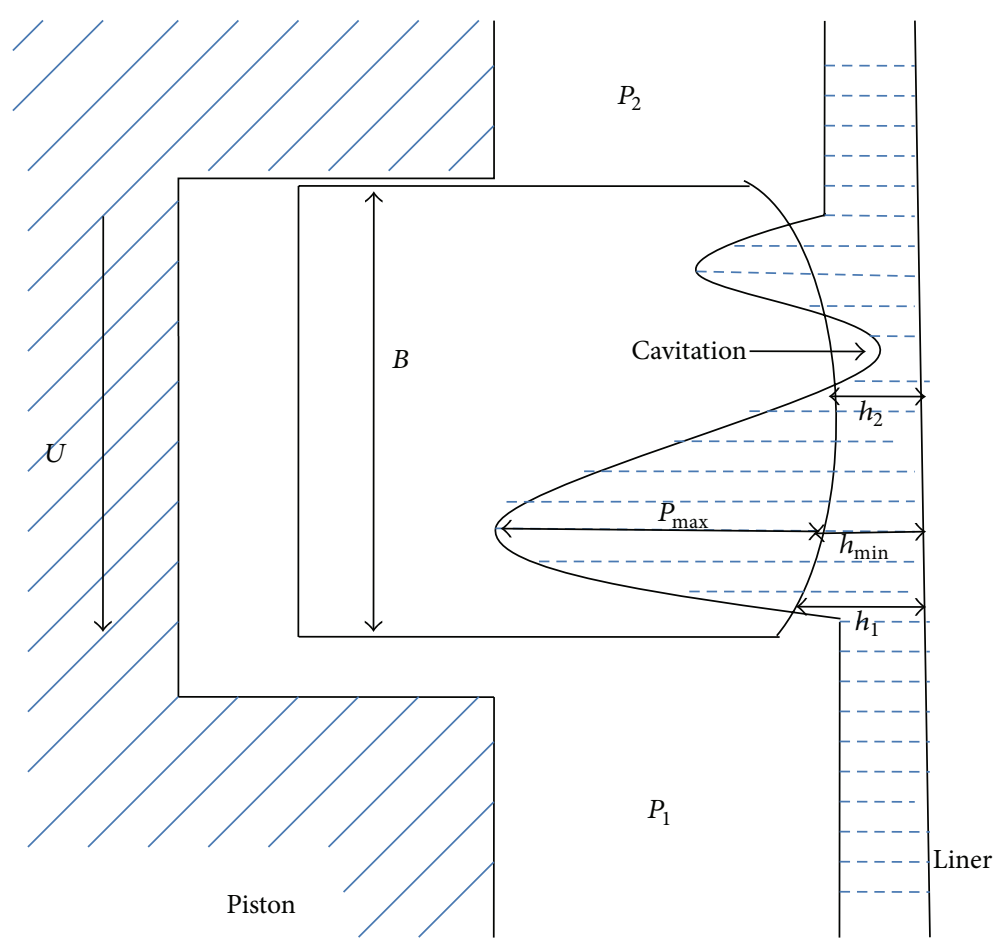

Figure 2: Schematic of hydrodynamic oil film between liner and piston.

across the film thickness by ignoring the squeeze film effect, which normally occurs at TDC and BDC, that is, steady film thickness approximation yields, $d h / d t=0$, Reynolds equation would reduce to

$$
\frac{\partial}{\partial x}\left(\frac{h^{3} \partial P}{\partial x}\right)=6 \eta\left(\frac{U d h}{d x}\right) .
$$

For hydrodynamic lubrication regime, piston ring assembly minimum oil film thickness and friction power loss are given by Furuhama and Sasaki [6] as follows:

$$
\begin{aligned}
& h_{\min } \alpha\left(\frac{\eta U}{W}\right)^{1 / 2}, \\
& \operatorname{FP} \alpha\left(\eta U^{3} W\right)^{1 / 2},
\end{aligned}
$$

" $U$ " is piston velocity, " $h_{\min }$ " is film thickness, " $\eta$ " is dynamic viscosity of lubricant, and " $W$ " is load on back of piston ring. It may be observed from the above relation that friction power loss is more influenced by piston speed as compared to oil viscosity.

Petroff equation $[7,15]$ for journal bearings, under light loaded conditions, is given in the following:

$$
\begin{gathered}
h_{\text {min }} \approx c, \\
\mathrm{FP}=\frac{2 \pi \eta \omega^{2} L R^{3}}{c},
\end{gathered}
$$

where FP is the friction power loss (watts), $\eta$ is the lubricant dynamic viscosity $(\mathrm{mPa} \cdot \mathrm{s})$ appropriate to the bearing, $\omega$ is the engine's angular speed ( $\mathrm{rad} / \mathrm{s}), L$ is the bearing width $(\mathrm{m}), R$ is the bearing radius $(\mathrm{m})$, and $c$ is the bearing radial clearance (m). It may be observed from the Petroff equation that friction power loss varies linearly with lubricant viscosity and square of angular speed. Friction power loss in hydrodynamic lubrication conditions (piston ring assembly and bearings) is actually a combined effect of load, piston speed, oil film thickness, and oil viscosity.

The test matrix comprised of the factors such as speed, load, oil viscosity, response parameter, and friction power (FP) is shown in Table 4 for the steady state conditions. The test results revealed that friction power response is influenced by the variables such as engine speed, load, and engine lubricant type (viscosity). Since the experiments were conducted in controlled conditions for both engine lubricants, the effect of engine lubricant temperature may be neglected as both lubricants were tested under identical conditions.

Analysing the factorial design for the dominant factor with $95 \%$ confidence level, a factorial fit was used which includes main effects, first order interactions and second order interactions whose ANOVA table thus produced is given in Table 5. In order to determine the significant factors among the main effects, two-way effects and three-way effect, the $P$ value was used for screening these parameters. It is noteworthy to state that all main effects, speed, load, oil viscosity, and 2 two-way interactions, speed-load and speedviscosity, are significant parameters which affect engine friction power with $95 \%$ confidence level, as $P$ value is less than 0.05 for all these five cases. 
TABLE 5: General factorial regression: FP versus speed, load, and viscosity.

(a) Factor information

\begin{tabular}{lcc}
\hline Factor & Levels & Values \\
\hline Speed & 2 & 1000,2000 \\
Load & 3 & $50,200,350$ \\
Viscosity & 2 & $11.0,14.5$ \\
\hline
\end{tabular}

(b) Analysis of variance

\begin{tabular}{lccccc}
\hline Source & DF & Adj SS & Adj MS & $F$ value & $P$ value \\
\hline Model & 11 & 356.141 & 32.376 & 47.62 & 0.000 \\
$\quad$ Linear & 4 & 262.786 & 65.696 & 96.62 & 0.000 \\
$\quad$ Speed & 1 & 188.104 & 188.104 & 276.65 & 0.000 \\
$\quad$ Load & 2 & 68.244 & 34.122 & 50.18 & 0.000 \\
$\quad$ Viscosity & 1 & 6.438 & 6.438 & 9.47 & 0.010 \\
2-way interactions & 5 & 92.847 & 18.569 & 27.31 & 0.000 \\
$\quad$ Speed $*$ load & 2 & 85.872 & 42.936 & 63.15 & 0.000 \\
$\quad$ Speed $*$ viscosity & 1 & 6.752 & 6.752 & 9.93 & 0.008 \\
$\quad$ Load $*$ viscosity & 2 & 0.223 & 0.112 & 0.16 & 0.850 \\
3-way interactions & 2 & 0.509 & 0.254 & 0.37 & 0.696 \\
$\quad$ Speed $*$ load $*$ viscosity & 2 & 0.509 & 0.254 & 0.37 & 0.696 \\
Error & 12 & 8.159 & 0.680 & & \\
\hline Total & 23 & 364.301 & & & \\
\hline
\end{tabular}

(c) Model summary

\begin{tabular}{lccc}
\hline$S$ & $R$-sq & $R$-sq (adj) & $R$-sq (pred) \\
\hline 0.824578 & $97.76 \%$ & $95.71 \%$ & $91.04 \%$ \\
\hline
\end{tabular}

(d) Fits and diagnostics for unusual observations

\begin{tabular}{lccccc}
\hline Obs & FP & Fit & Resid & Std Resid & \\
\hline 7 & 7.020 & 8.400 & -1.380 & -2.37 & $R$ \\
24 & 9.780 & 8.400 & 1.380 & 2.37 & $R$ \\
\hline
\end{tabular}

$R$ : large residual.

3.1. Friction Power Prediction. An empirical relation for predicting friction power (FP) of the engine based on the significant factors is shown below in what follows:

$$
\begin{aligned}
\mathrm{FP}= & -1.69+0.37352 A+0.30925 B-0.61333 C \\
& -0.029325 A B+0.060619 A C .
\end{aligned}
$$

(It is important to note that in the above empirical equation, the input values for speed in rpm are to be divided by 100 ; e.g., $1000 \mathrm{rpm}$ is to be put as 10 and input values of load are to be divided by 10 ; e.g., $50 \mathrm{Nm}$ is to be put as 5 .)

Figures 3 and 4 compare the experimental friction power (FP-Exp) with predicted friction power (FP-Pred) for both engine lubricants, that is, SAE $15 \mathrm{~W}-40$ and SAE 10W-30. It is noteworthy to state that predicted friction power values for both engine lubricants are very close to the experimental values.

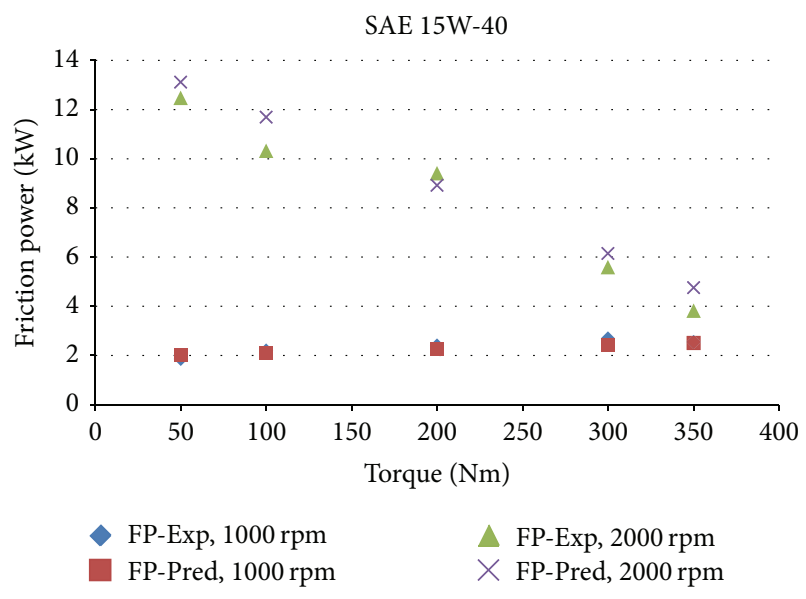

Figure 3: Experimental Friction Power (FP-Exp) and Predicted Friction Power (FP-Pred) in kW for Engine lubricant SAE 15W-40.

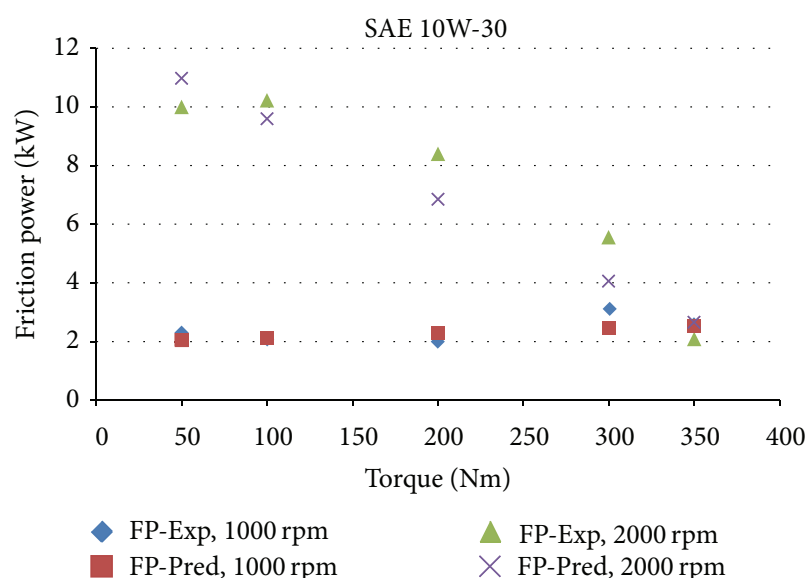

FIGURE 4: Experimental friction power (FP-Exp) and predicted friction power (FP-Pred) in kW for engine lubricant SAE 10W-30.

\subsection{Response Surface Methodology (RSM) Analysis}

3.2.1. Effect of Speed on Friction Power. It may be observed from the data given in Table 4 that the friction power (FP) of an engine running on lubricant SAE10W-30 increased by 4 to 5 times, with the increase in engine speed from $1000 \mathrm{rpm}$ to $2000 \mathrm{rpm}$ although load was kept constant at $50 \mathrm{Nm}$ (run order $8,10 \& 2,22$ ). Similar trend was observed for the engine running on engine lubricant SAE15W-40; in this case friction power (FP) rose up to 6 folds (refer run order $6,19 \& 12$, 13). Hence it may be deciphered from the above results that at high speed and low load, simulating the hydrodynamic lubrication conditions, engine friction power is significantly influenced by the speed of an engine.

These facts may also be illustrated by contour plots and response surfaces. Points on a contour plot, that have the same response, are connected to produce contour lines of constant responses. In the contour plots, the darkest area indicates the region where the response (friction power) is highest. As the colours get lighter, the response decreases. 

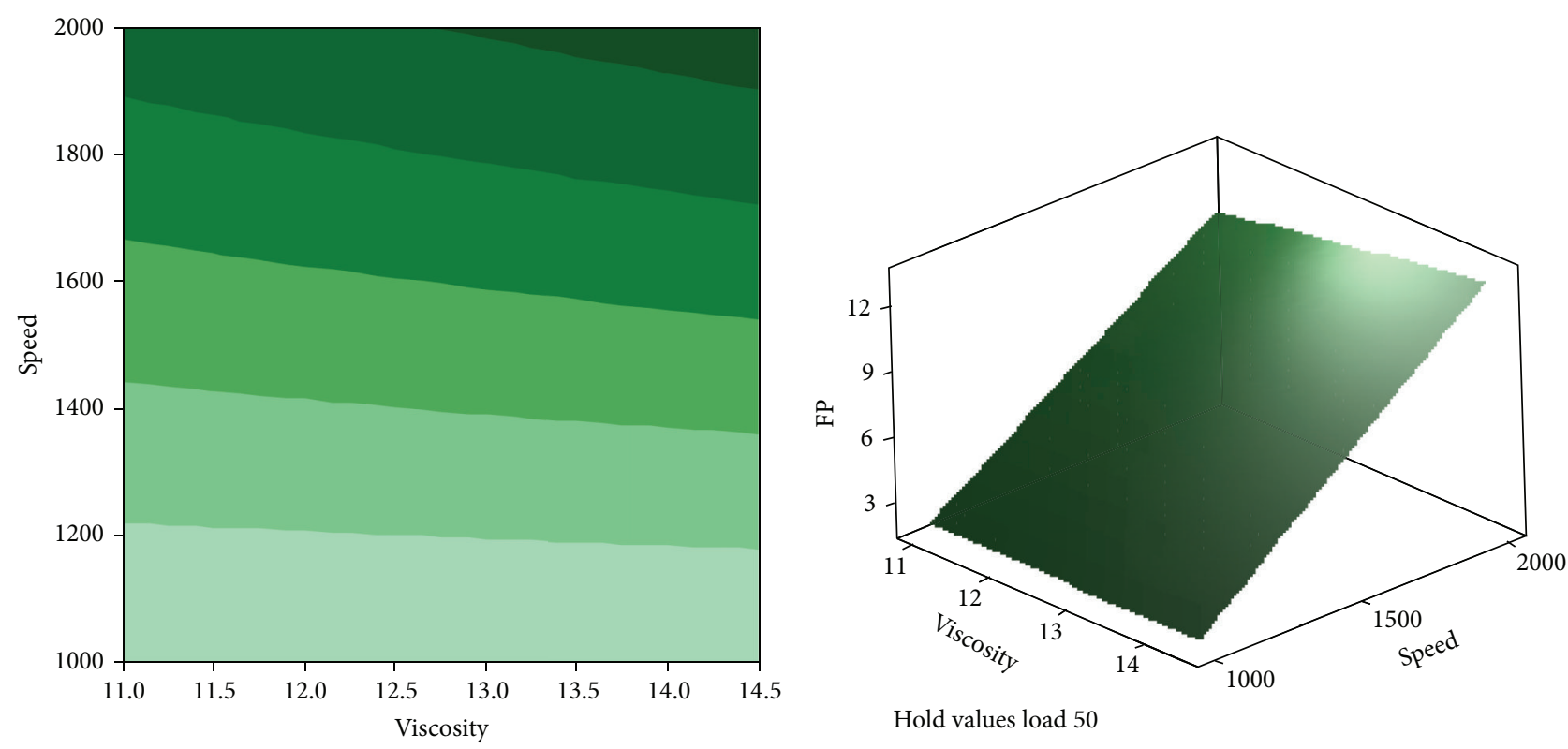

Hold values load 50

FP

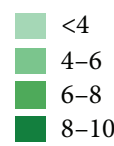

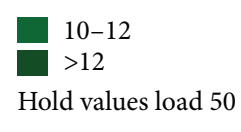

(a) (b)

Figure 5: (a) Contour plot of FP versus viscosity and speed at a load of $50 \mathrm{Nm}$. (b) Response surface plot of FP versus viscosity and speed at a load of $50 \mathrm{Nm}$.

Acute or sudden changes in colour correspond to sudden or steep change in friction power. The response surface plot, on the other hand, is a three-dimensional surface graph that represents the functional relationship between the response and the experimental factors. As both these plots can show only two factors at a time, while holding any other factors at a constant level, they are only valid under ceteris paribus conditions. If there is a change in holding levels, the response surface and contour plot change as well, sometimes drastically. Figures 5(a) and 5(b) illustrates the variation of FP as a function of speed and viscosity at the load of $50 \mathrm{Nm}$. The plots represent a rising ridge (increasing friction power) towards higher speed. Effect of viscosity is only prominently seen at high speed, indicated by inclined ridges in contour plot of Figure 5(a), whereas at low speed these ridges are almost straight indicating very less effect of viscosity on friction power.

3.2.2. Effect of Load on Friction Power. Engine load also plays a vital role in engine friction. At higher engine speed, that is, $2000 \mathrm{rpm}$, reduction in friction power was observed with increasing load from $50 \mathrm{Nm}$ to $350 \mathrm{Nm}$ for both engine lubricants, SAE 10W-30 and SAE 15W-40 (refer run order 2 $\& 22,9 \& 20,12 \& 13,4 \& 14)$. This may be explained with the help of the well-known fact that the contribution of friction as a percentage of indicated power output reduces as load increases. At lower speed, $1000 \mathrm{rpm}$ and for all three load

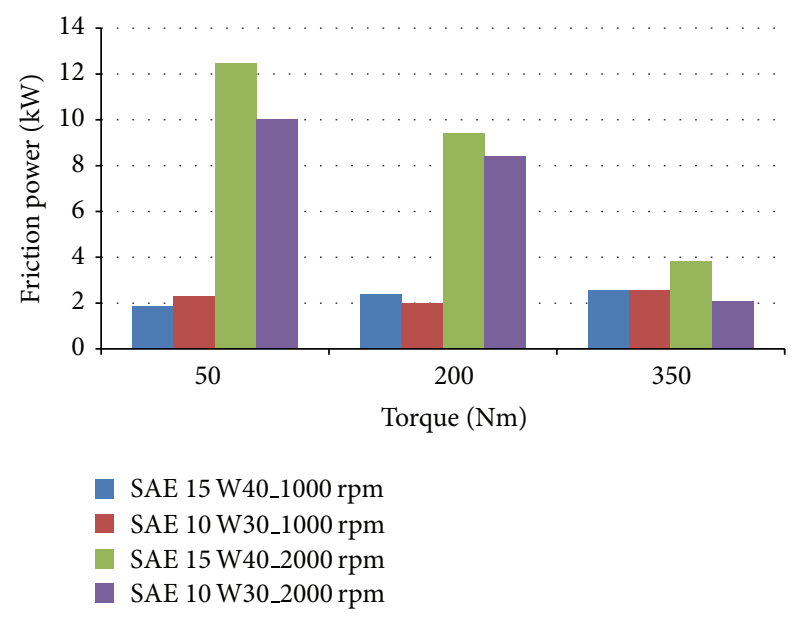

Figure 6: Comparison of friction power at different load and viscosity.

levels 50, 200, and $350 \mathrm{Nm}$, there is marginal change in engine friction power (run orders 8, 15, 23 and 6, 17,21) for both engine oils.

It is illustrated in Figure 6 that, with increase in load from $50 \mathrm{Nm}$ to $350 \mathrm{Nm}$, change in FP value for speed of $2000 \mathrm{rpm}$ has been reduced to a level comparable to the speed of $1000 \mathrm{rpm}$ for both engine oils. In the contour and response 


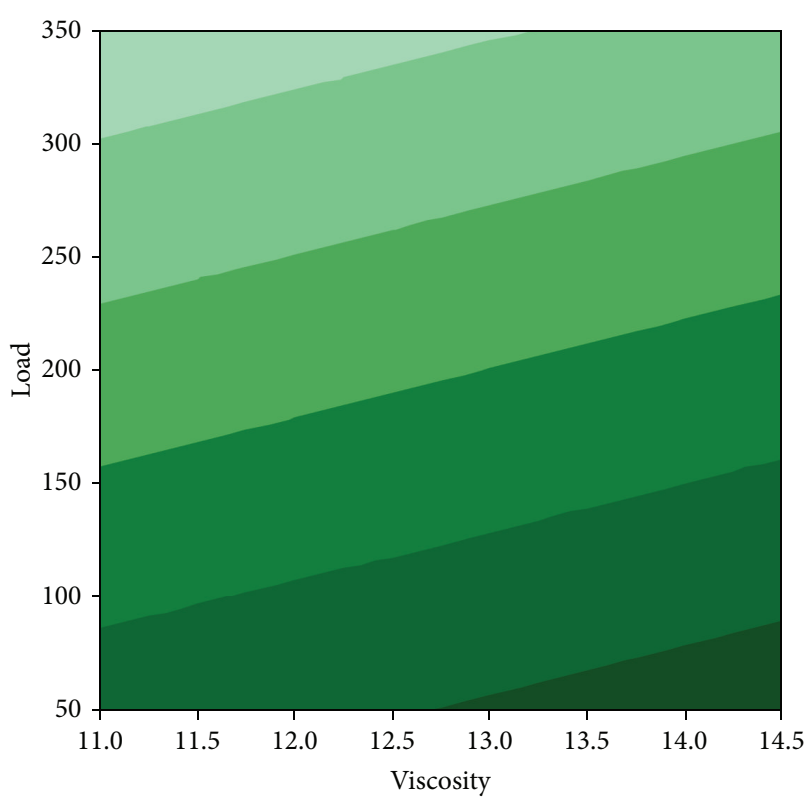

FP

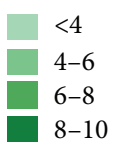

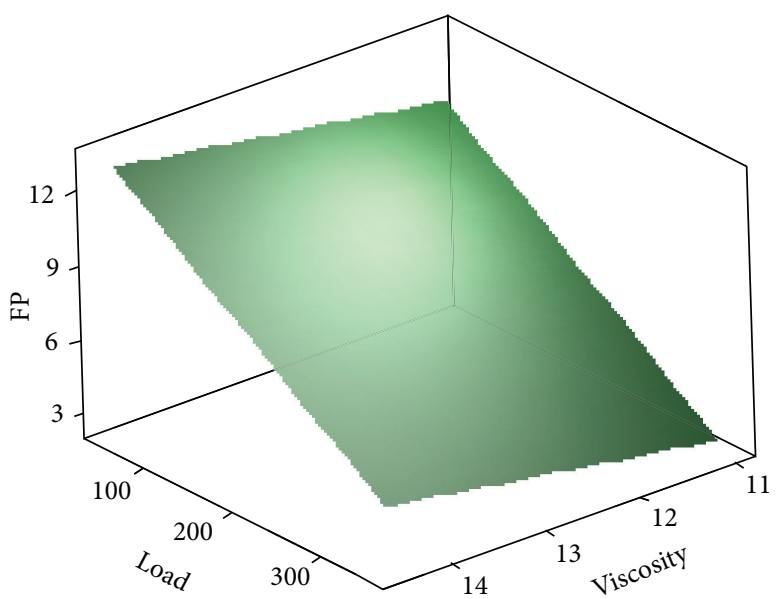

Hold values speed 2000 

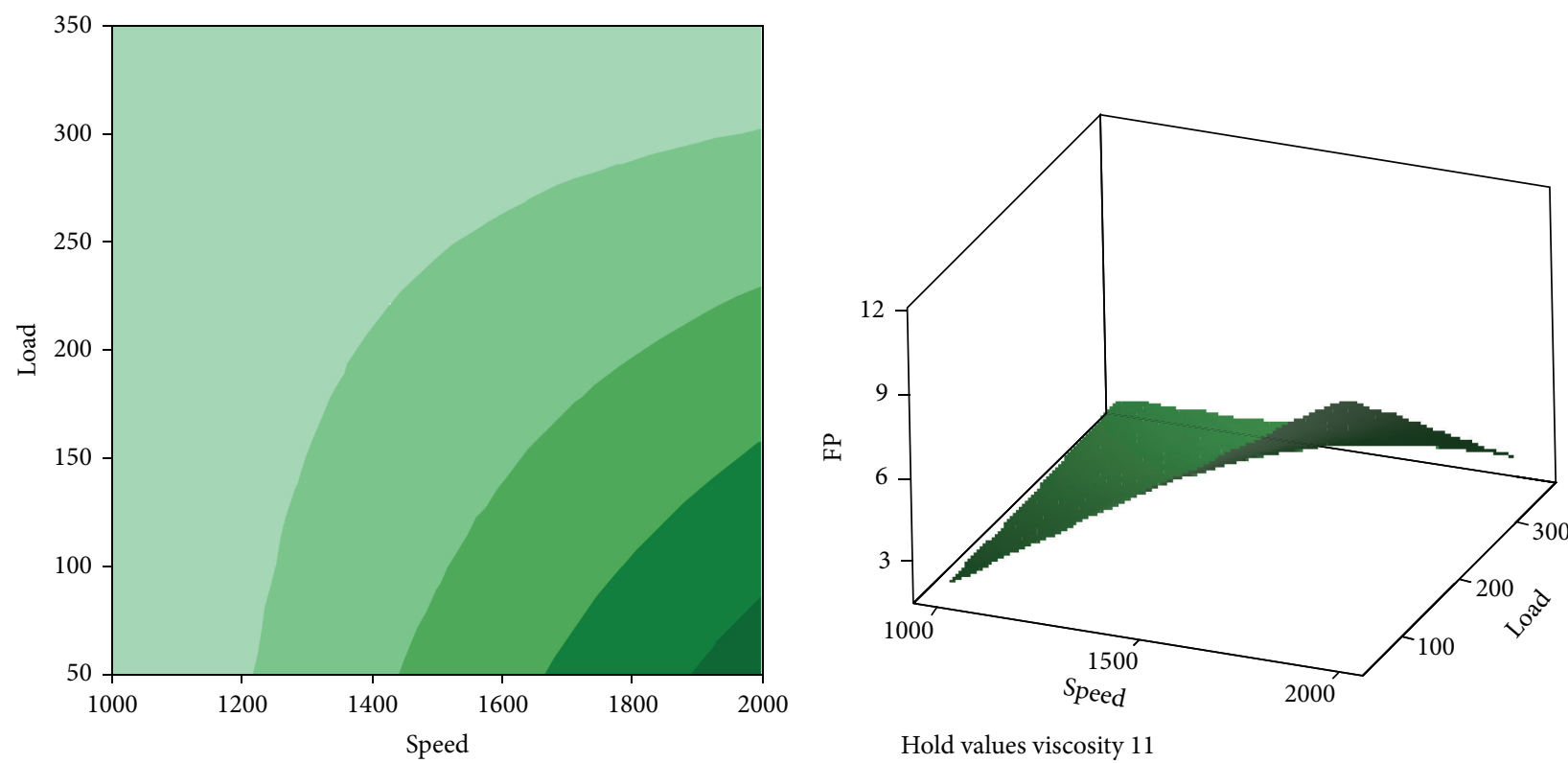

Hold values viscosity 11

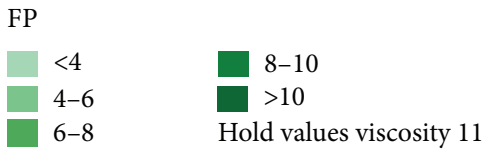

(a)

(b)

Figure 8: (a) Contour plot of FP versus load and speed at a viscosity of $11 \mathrm{cSt}$. (b) Response surface plot of FP versus load and speed at a viscosity of $11 \mathrm{cSt}$.
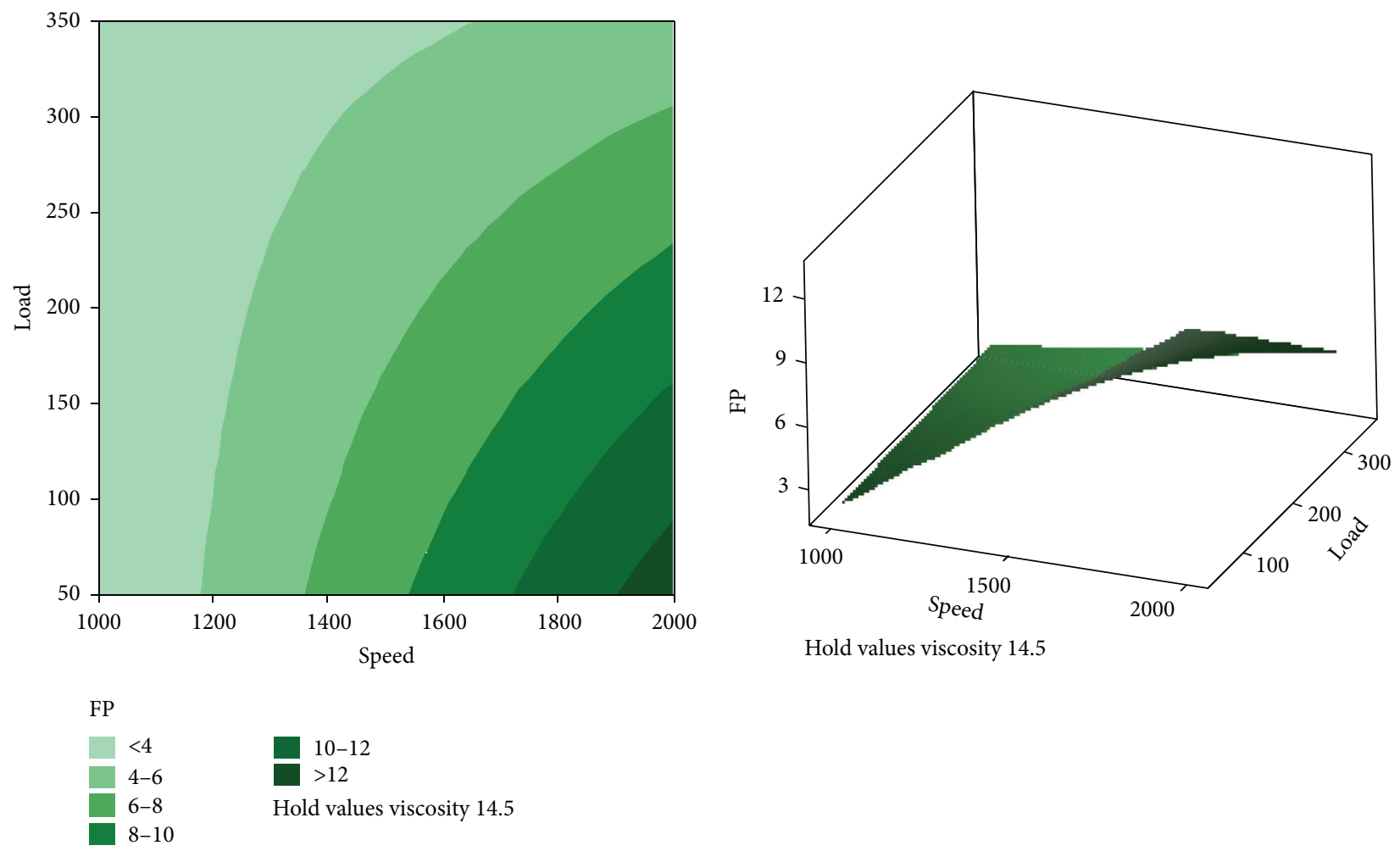

(a)

(b)

FIGURE 9: (a) Contour plot of FP versus load and speed at a viscosity of $14.5 \mathrm{cSt}$. (b) Response surface plot of FP versus load and speed at a viscosity of $14.5 \mathrm{cSt}$. 
a fired engine. Predicted results of friction power are in good agreement with measured values of steady state operating points.

(iii) Contour plots and RSM illustrates that the engine friction power increases approximately four to six times when engine speed increases from $1000 \mathrm{rpm}$ to $2000 \mathrm{rpm}$ at constant load of $50 \mathrm{Nm}$. Hence, speed plays a dominant role in influencing engine friction power.

(iv) Engine friction power, with increase in load from $50 \mathrm{Nm}$ to $350 \mathrm{Nm}$ at $2000 \mathrm{rpm}$ reduces by a factor of 3 to 4 for both engine lubricants portraying its importance in influencing friction power. It may be concluded that at higher speeds, the interaction effect of load and viscosity affects friction power substantially.

(v) At higher speeds, engine lubricant viscosity plays a vital role in influencing engine friction power loss (assuming hydrodynamic conditions) whereas at low speeds the effect of engine lubricant viscosity on engine friction power is insignificant.

$\begin{array}{ll}\text { Abbreviations } \\ B: & \text { Width of the ring } \\ C: & \text { Bearing radial clearance } \\ \partial P / \partial x: & \text { Pressure gradient along the width of piston ring } \\ \partial P / \partial y: & \text { Pressure gradient in circumferential direction of } \\ & \text { a piston ring } \\ \partial P / \partial z: & \text { Pressure gradient through film thickness } \\ d h / d x: & \text { Film thickness gradient along the ring width } \\ h: & \text { Film thickness } \\ h_{1}: & \text { Film thickness at the entrance } \\ h_{2}: & \text { Film thickness at the start of cavitation region } \\ h_{\min }: & \text { Film thickness corresponding to the maximum } \\ & \text { pressure } \\ P_{1} \text { and } P_{2}: \begin{array}{l}\text { Pressure at entrance and exit of ring face } \\ U:\end{array} & \text { Velocity of piston } \\ V: & \text { Velocity of a ring in circumferential direction } \\ W: & \text { Load on back of piston ring } \\ \eta: & \text { Dynamic viscosity of the lubricant } \\ \omega: & \text { Angular speed (rad/s). }\end{array}$

\section{Conflict of Interests}

The authors declare that there is no conflict of interests regarding the publication of this paper.

\section{Acknowledgments}

The authors are indebted to Dr. M. O. Garg, Director IIP, Dehradun, for being the main source of inspiration behind this paper. The authors would like to acknowledge the technical support provided by the school of computing and engineering, University of Huddersfield, UK, for undertaking the experiments and Mr. Ankur Pathak for his kind help. The authors would also like to thank British Council, UK, and Department of Science and Technology, India, for approving a joint project UKIERI research award.

\section{References}

[1] J. B. Heywood, Fundamentals of Internal Combustion Engine, Mechanical Engineering, McGraw-Hill, New York, NY, USA, 1988.

[2] C. M. Taylor, Ed., Engine Tribology, Tribology Series 26, Elsevier Science, 1993.

[3] A. Comfort, "An introduction to heavy-duty diesel engine frictional losses and lubricant properties affecting fuel economypart I," SAE Technical Paper 2003-01-3225, SAE International, 2003.

[4] R. Gligorijevic, J. Jevtic, and G. Jaksic, "Contribution of engine oil to diesel exhaust emission and friction reduction," in The Annuals of University of Galati Fascicle VIII, Tribology, 2003.

[5] R. I. Taylor, R. T. Dixon, F. D. Wayńe, and S. Gunsel, "Lubricants \& energy efficiency: life-cycle analysis," Tribology and Interface Engineering Series, vol. 48, pp. 565-572, 2005.

[6] S. Furuhama and S. Sasaki, "Effect of oil properties on piston frictional forces," JSAE Review, pp. 68-76, 1984.

[7] R. I. Taylor, "Lubrication tribology and motorsport," SAE Technical Paper 2002-01-3355, 2002.

[8] R. I. Taylor, "Engine friction: the influence of lubricant rheology," Proceedings of the Institution of Mechanical Engineers J: Journal of Engineering Tribology, vol. 211, no. 3, pp. 235-246, 1997.

[9] D. Singh, M. K. Shukla, S. Singh et al., "Fuel economy of SI vehicle fueled by ethanol/gasoline blends-role of engine lubricant viscosity," SAE Technical Paper 2013-01-0051, 2013.

[10] R. A. Mufti and M. Priest, "Experimental evaluation of pistonassembly friction under motored and fired conditions in a gasoline engine," ASME Journal of Tribology, vol. 127, no. 4, pp. 826-836, 2005.

[11] R. A. Mufti, M. Priest, and R. J. Chittenden, "Analysis of piston assembly friction using the indicated mean effective pressure experimental method to validate mathematical models," Proceedings of the Institution of Mechanical Engineers, Part D: Journal of Automobile Engineering, vol. 222, no. 8, pp. 1441-1457, 2008.

[12] R. A. Mufti and M. Priest, "Effect of engine operating conditions and lubricant rheology on the distribution of losses in an internal combustion engine," Journal of Tribology, vol. 131, no. 4, pp. 1-9, 2009.

[13] R. Roshan, M. Priest, A. Neville et al., "Friction modelling of tribofilm performance in a bench tribometer for automotive engine lubricants," Proceedings of the Institution of Mechanical Engineers Part J: Journal of Engineering Tribology, vol. 222, no. 3, pp. 357-367, 2008.

[14] V. Dagostino, P. Maresca, and A. Senatore, "Theoretical analysis for friction losses minimization in piston rings," in Proceedings of the International Conference on Tribology, Parma, Italy, September 2006.

[15] G. W. Stachowiak and A. W. Batchelor, Engineering Tribology, vol. 24 of Tribology Series, Elsevier, 1993. 

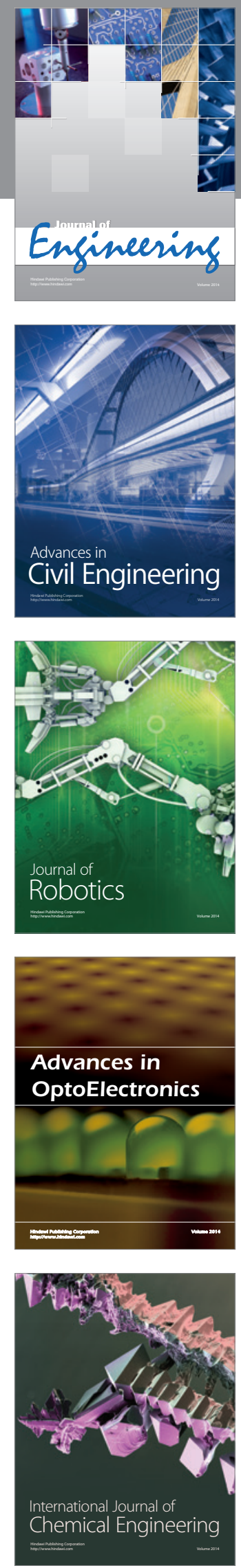

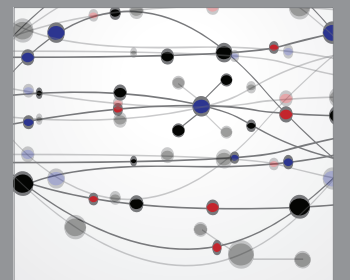

The Scientific World Journal
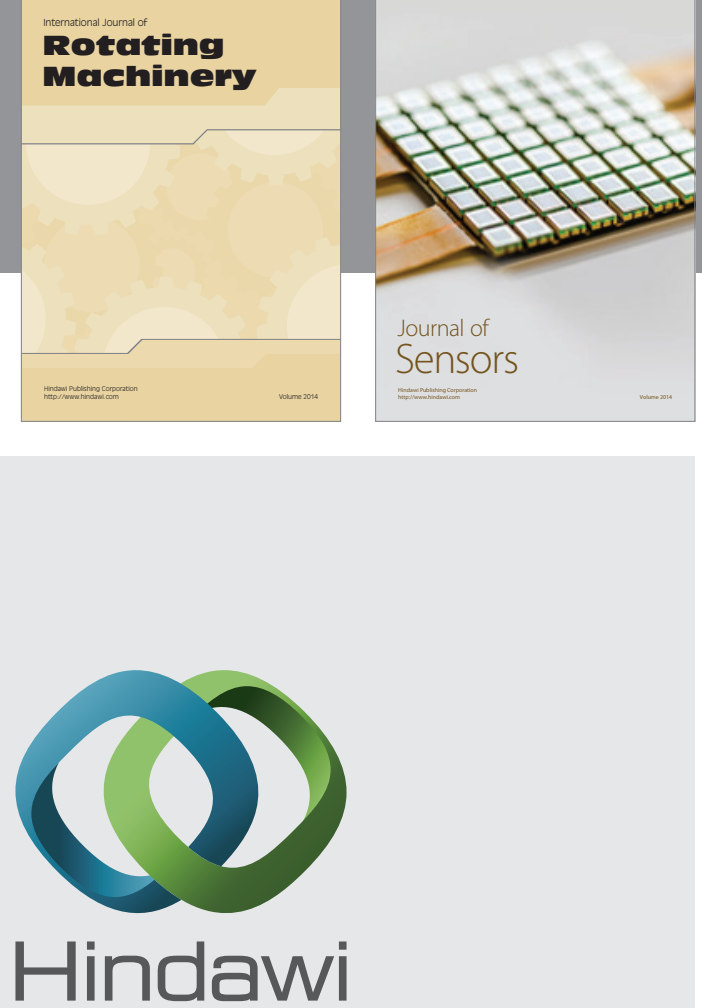

Submit your manuscripts at http://www.hindawi.com
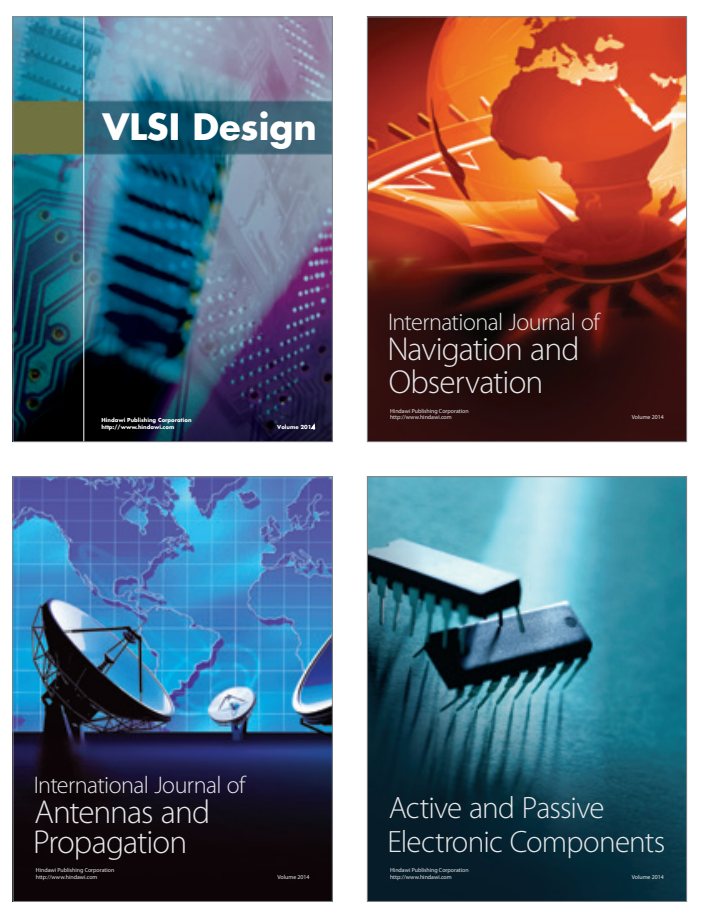
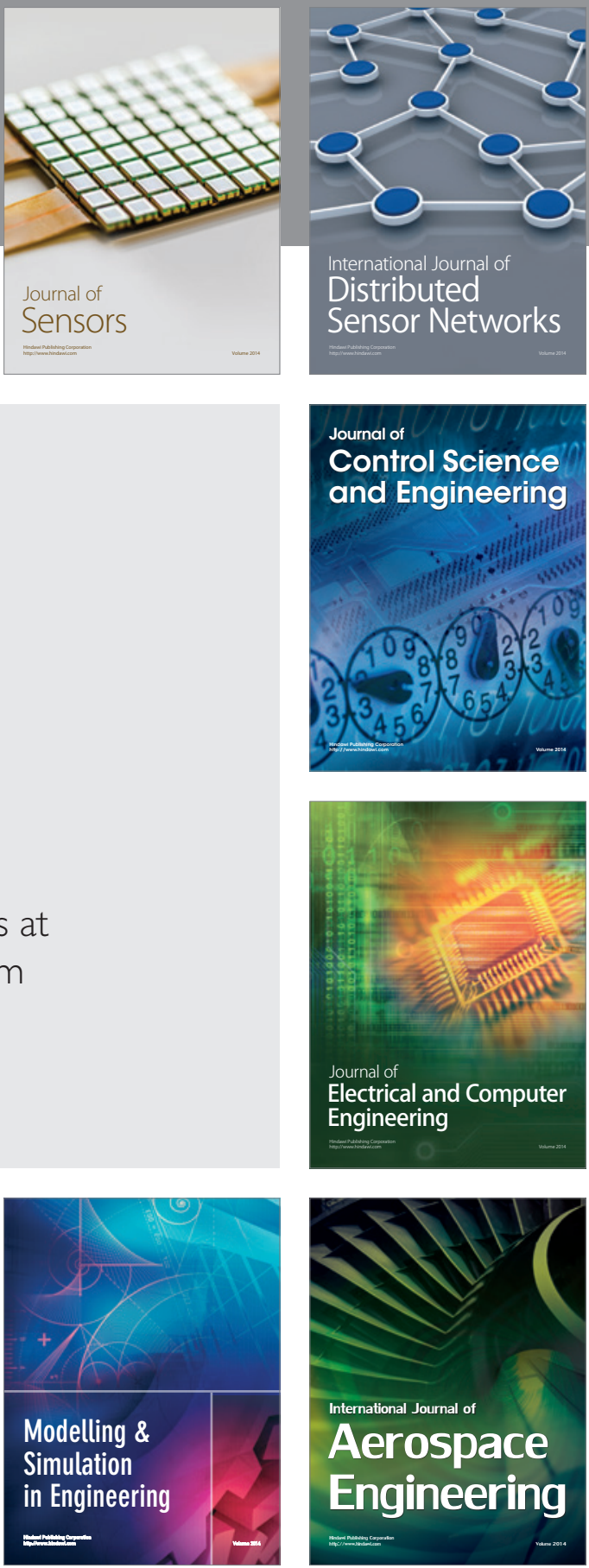

Journal of

Control Science

and Engineering
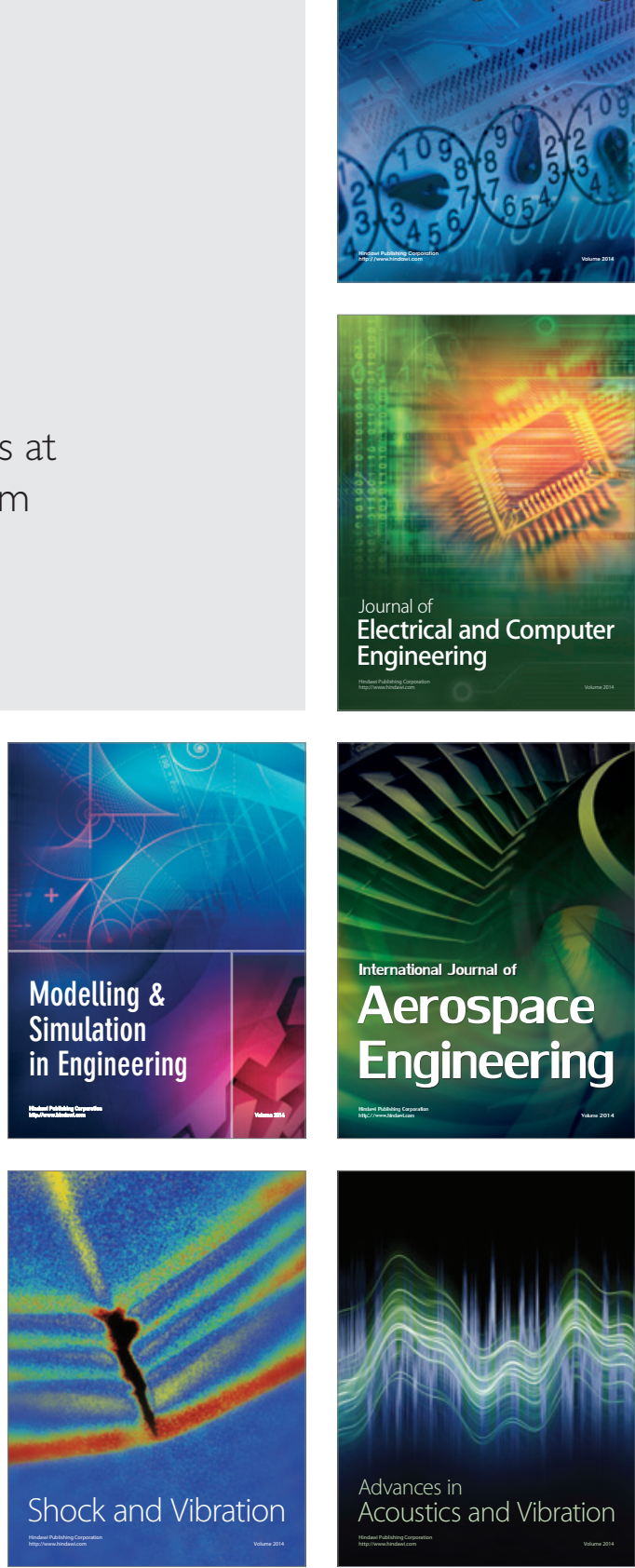